\title{
Large trials, new knowledge: the changing face of COPD management
}

\author{
Anthony De Soyza ${ }^{1}$ and Peter M.A. Calverley ${ }^{2}$
}

\section{Affiliations:}

${ }_{1}^{1}$ Institute of Cellular Medicine, Newcastle University Medical School, Newcastle upon Tyne, UK.

${ }^{2}$ Department of Clinical Sciences, University of Liverpool, University Hospital Aintree, Liverpool, UK.

\section{Correspondence:}

Peter M.A. Calverley, School of Clinical Science (Aintree campus), University Hospital Aintree, Longmoor Lane, Liverpool, L9 7AL, UK.

E-mail: pmacalaliverpool.ac.uk

ABSTRACT Large, well-designed, drug-treatment trials have allowed useful advances to be made in the treatment and diagnosis of chronic obstructive pulmonary disease (COPD). The two main clinical trial designs that provide evidence of effectiveness are randomised controlled trials (RCTs) and observational studies. RCTs are generally considered to provide more robust evidence than that obtained from observational studies and can generate informative secondary analyses in addition to the primary research query. In COPD, however, well-designed comparator-controlled RCTs, although successful, have been shown to have some limitations, such as a lack of generalisability. The findings of observational studies, whilst prone to bias, can generate valuable data and have also provided useful information relating to the efficacy of treatments in the current COPD management guidelines. This review focuses on major COPD studies published since 2007 (including UPLIFT, TIOSPIR, ECLIPSE and COPDGene), and assesses the influence such RCTs and large observational studies have had on our knowledge of COPD, and how these may impact future trial designs.

@ERSpublications

Findings of RCTs and large observational studies contribute significantly to our knowledge of COPD http://ow.ly/J1rp0

This article has supplementary material available from erj.ersjournals.com

Received: Sept 302014 | Accepted after revision: Feb 012015 | First published online: March 182015

Support statement: Medical writing support for this manuscript was provided by David Candlish of inScience Communications (Springer Healthcare, Chester, UK). This support was funded by an unrestricted medical education grant from AstraZeneca. Funding information for this article has been deposited with FundRef.

Conflict of interest: Disclosures can be found alongside the online version of this article at erj.ersjournals.com

Copyright OERS 2015 


\section{Introduction}

The past two decades have seen an explosion of studies into all aspects of the causes and care of patients with chronic obstructive pulmonary disease (COPD). This effort reflects the increasing disease burden and mortality from COPD [1-3]. Tobacco consumption is still the principal, but not the sole, cause of COPD [4], and changes in tobacco use are shifting the demographic burden of disease in Western countries to an older age group [5, 6]. Smoking cessation remains central to disease management but has relatively limited impact once patients become symptomatic, at which point the healthcare-related costs of COPD rise sharply [6, 7]. Many other treatment options have been investigated but none has reversed the loss of lung function that characterises COPD.

Nonetheless, a small improvement in the wellbeing of a large percentage of people suffering from a common disease like COPD can have a significant healthcare impact. To detect small differences in patient outcomes, increasing numbers of people must be studied for relatively extended periods. This reflects the lack of reliable intermediate markers predicting clinical change, despite recent efforts at seeking novel surrogate endpoints $[8,9]$. Large numbers of subjects are also needed to reliably identify a true treatment effect, given the heterogeneity of the disease and the intermittent nature of some of its key outcomes, such as exacerbations [10]. While randomised controlled trials (RCTs) remain the best way of establishing whether a treatment works, there are concerns about their generalisability [11-13]. Hence, there is increasing emphasis on observational "real-world" studies, where cohorts of patients are collected within an administrative database and subsequently followed. Such data are complementary to that obtained by RCTs and the successful integration of these two different views on clinical care is still in its infancy (table 1).

Some 7 years ago, one of the authors (P.M.A. Calverley) reviewed the available data generated by large clinical trials in COPD [15]. Several issues considered then have now been addressed in new studies. Data from even larger clinical studies, some of which have reported or are underway, are likely to provide answers to questions posed but not resolved in 2007.

We undertook a literature review of COPD studies enrolling $>500$ participants (an arbitrary threshold agreed at the outset). We supplemented this with data from individual studies known to us that either support or challenge the reports from larger trials. We identified 74 studies in total, comprising 49 RCTs and 25 observational studies. Inevitably, we have been selective about the topics discussed and more information about the individual studies is provided in the online supplementary material. We also draw

TABLE 1 Advantages and limitations of randomised controlled trials (RCTs) and observational studies

\begin{tabular}{|c|c|c|c|}
\hline & RCTs & Pragmatic RCTs & Observational studies \\
\hline Advantages & $\begin{array}{l}\text { Rigorous experimental design } \\
\text { Randomisation and blinding } \\
\text { Defined controls } \\
\text { Robust analysis methods } \\
\text { Limitation of confounders } \\
\text { Established route into regulatory } \\
\text { approvals }\end{array}$ & $\begin{array}{l}\text { Pragmatic experimental design } \\
\text { Nonselected population will include } \\
\text { those with significant comorbidities, } \\
\text { as seen in COPD } \\
\text { Randomisation and blinding } \\
\text { Usual care } \\
\text { Normal levels of therapy adherence } \\
\text { Logistical and ethical feasibility } \\
\text { Prolonged follow-up possible } \\
\text { (dependent on funding) }\end{array}$ & $\begin{array}{l}\text { Nonselected population will include those } \\
\text { with significant comorbidities, as seen } \\
\text { in COPD } \\
\text { Limited expense/intensity } \\
\text { Usual care/“head-to-head” comparisons } \\
\text { Normal levels of therapy adherence } \\
\text { Logistical and ethical feasibility } \\
\text { Able to evaluate complex therapies } \\
\text { Utility in detecting rare or chronic side } \\
\text { effects } \\
\text { Routine practice setting } \\
\text { Prolonged follow-up possible }\end{array}$ \\
\hline Limitations & $\begin{array}{l}\text { Constrained population means } \\
\text { limited generalisation } \\
\text { Setting and monitoring bias } \\
\text { Expense often limits prolonged } \\
\text { duration and sample size } \\
\text { Logistical and ethical/normal care } \\
\text { restrictions } \\
\text { Unsuitable for complex treatment } \\
\text { studies } \\
\text { Unsuitable for prolonged evaluation } \\
\text { of side-effects/detecting rare events } \\
\text { Short duration }\end{array}$ & $\begin{array}{l}\text { Not yet established route into } \\
\text { regulatory approvals } \\
\text { Duration still likely to be } \\
\text { limited by funding } \\
\text { Unsuitable for complex } \\
\text { treatment studies }\end{array}$ & $\begin{array}{l}\text { Not yet established route into regulatory } \\
\text { approvals } \\
\text { Lack of randomisation or patient selection } \\
\text { brings confounding factors } \\
\text { Absence of blinding } \\
\text { Limitations to certain healthcare settings } \\
\text { with databases } \\
\text { Bias } \\
\text { Immortality bias } \\
\text { Usual care bias } \\
\text { Reporting/recording bias }\end{array}$ \\
\hline
\end{tabular}

COPD: chronic obstructive pulmonary disease. Adapted from [14]. 
the reader's attention to the helpful evidence tables available online from the UK National Institute of Clinical Health and Excellence as part of the 2010 review of drug therapy in COPD [16].

\section{Progress in concepts of COPD since 2007}

In 2007, the largest COPD treatment study was the Towards a Revolution in COPD Health (TORCH) trial, involving just over 6000 patients followed for 3 years [17]. This has since been joined by the Understanding Potential Long-term Impacts on Function with Tiotropium (UPLIFT) study [18], where a similar number of patients were followed for 4 years, and the more recent Tiotropium Safety and Performance in Respimat (TIOSPIR) study, where 17137 people were followed until $>1000$ had died, providing $\geqslant 2$ years of data in $85 \%$ of this large number of subjects [19]. We reviewed some of the difficulties in the statistical approach to expressing exacerbations in 2007. Subsequent data have shown that exacerbations cluster in time [20], thereby justifying the complex statistical methodologies used to describe these events [21]. Identifying the time to a new exacerbation after treatment randomisation has been used in large studies such as the Prevention of Exacerbations with Tiotropium in COPD (POET-COPD) study [22]. However, time to first event is not exactly the same as total number of events experienced. Additionally, regulators may request other primary outcome measures; hence, most studies now report both a model exacerbation rate and the time to first exacerbation.

In most studies, exacerbations are identified by the need to change treatment, and especially the prescription of antibiotics and/or corticosteroids. Greater sensitivity in detecting exacerbation symptoms is provided by daily diary card recordings. More recently, the Exacerbation of Chronic Pulmonary Disease Tool for Patient-Reported Outcomes (EXACT-PRO) has been shown to be effective at defining the resolution of these events [23]. However, there are still uncertainties about determining when an event has concluded and, for the EXACT-PRO, when it begins. Whatever method is used, the total number of events is larger than relying on treatment-defined exacerbations and this means that fewer individuals need to be studied to determine whether a treatment is effective.

By 2007, the usefulness of bronchodilator reversibility testing had been challenged, largely as a result of data from the Inhaled Steroids in Obstructive Lung Disease in Europe (ISOLDE) study [24]. Subsequently, the limitations of bronchodilator reversibility testing have been confirmed by the meticulously collected data from the UPLIFT trial, where TASHKIN et al. [25] showed that the absolute increase in forced expiratory volume in $1 \mathrm{~s}\left(\mathrm{FEV}_{1}\right)$ after a bronchodilator falls in parallel with baseline lung function. This makes a reversible response less likely in severe disease when a volume criterion is incorporated in the definition [24]. There was no relationship between baseline reversibility status and subsequent clinical progress [24]. These findings were confirmed by equally extensive observations from the Evaluation of COPD Longitudinally to Identify Predictive Surrogate Endpoints (ECLIPSE) longitudinal observational cohort study [26], which found that the absolute increase in FEV1 in patients with moderate COPD was similar to that in healthy smokers. This topic has been reviewed in detail [27].

The importance of structural and functional heterogeneity within emphysematous lungs was recognised by 2007 in the NETT (National Emphysema Treatment Trial), in which lung volume reduction surgery was shown to be safer and more effective in patients with upper lobe predominant emphysema [28]. Similar problems apply when medical (endobronchial) lung volume reduction approaches, such as the implantation of valves, coils or glue to occlude the airways, have been used [29]. Although the study sizes here are still relatively modest and almost always smaller than our pre-defined threshold of 500 participants, they reinforce observations from larger studies that certain therapies need careful patient selection. For example, patients who have relatively preserved lobar fissures are more likely to show functional improvement after endobronchial valve placement [30]. More recent studies have emphasised the need to quantify the degree of collateral ventilation if medical lung volume procedures are to have any important effect [31-33]. These techniques have become increasingly popular, but we still lack studies on sufficient numbers of appropriately defined subjects, followed for long enough to ensure that the risk to the patient and the subsequent benefit are appropriate. Developing such medical technology trials (and maintaining blinding) is going to be a challenge for the next few years.

\section{RCTs of drug treatment}

Many questions have been examined by RCTs in the last 7 years. Since TORCH [17], only one study has considered overall mortality as its principal outcome [19]. Instead, the focus has been on reducing the number of COPD exacerbations, reflecting the clinical and economic impact of these events. Many studies still report changes in health status, predominantly using the St George's Respiratory Questionnaire (SGRQ), although there is now increasing use of the COPD Assessment Test [34]. To date, there are only limited data to suggest that treatments improve health status in patients who do not also show a reduction in exacerbation rate. Treatment of symptomatic patients without exacerbations and more modest 
spirometry impairment remains empirical. Newer trials with earlier intervention points will undoubtedly increase.

Among questions already addressed are the following.

Does regular use of an inhaled long-acting muscarinic antagonist modify the decline in FEV1? This was the primary end-point of the UPLIFT trial [18], where patients were randomised to either tiotropium or placebo on top of the normal background therapy. No significant difference was seen in the rate of decline of $\mathrm{FEV}_{1}$, although $70 \%$ of participants were also taking other, (potentially) effective long-acting inhaled drugs.

Is an inhaled corticosteroid/long-acting $\beta$-agonist combination better than a long-acting muscarinic antagonist at preventing exacerbations?

The 2-year Investigating New Standards for Prophylaxis in Reducing Exacerbations (INSPIRE) trial randomised patients with severe COPD and at least one previous exacerbation [35] to receive the inhaled corticosteroid (ICS)/long-acting $\beta$-agonist (LABA) combination fluticasone propionate plus salmeterol twice daily, or once-daily tiotropium. There were no differences in exacerbation rates between the groups, whether events were defined by healthcare use or diary cards. However, there were more deaths, hospitalisations and drop-outs in patients receiving therapy with a long-acting muscarinic antagonist (LAMA) alone, and health status was somewhat worse in this group. There were concerns about whether withdrawal from ICS exaggerated these effects but this did not appear to be the case, with similar rates of study withdrawal in both treatment arms over the first 3 months. There were differences in the way exacerbations were treated, with more patients on combination therapy being treated with antibiotics and more courses of corticosteroids being prescribed for patients taking tiotropium.

Is twice-daily LABA as effective as once-daily LAMA in exacerbation prevention?

The POET-COPD investigators randomised and followed 7376 patients for 1 year [22]. They found that significantly fewer exacerbations occurred when patients received a once-daily LAMA than a twice-daily LABA, irrespective of background use of ICS. Whether this reflects a specific pharmacological benefit from blocking muscarinic receptors or is a consequence of better sustained bronchodilation remains unclear. An equally well-powered, double-blinded trial contrasting one of the new once-daily LABAs with tiotropium would be welcome. The present data suggest that the once-daily LABA indacaterol is at least as effective as tiotropium in this regard [36-39].

\section{Are two bronchodilators better than one in exacerbation prevention?}

The development of new once-daily inhaled LABA drugs, such as indacaterol, vilanterol and olodaterol, as well as new LAMAs, such as umeclidinium, aclidinium and glycopyrronium, means that this question can be addressed and each of these agents may also be studied against single agents. The largest trial to date to report clinical endpoints as well as lung function, the SPARK study [40], compared bronchodilation with QVA149 (indacaterol and glycopyrronium) with glycopyrronium and tiotropium alone, and found that two bronchodilators were better than one in terms of reducing exacerbations. Much of this difference was driven by a reduction in events defined as mild symptomatic worsening rather than those that required medical therapy. Several other large studies have shown general equivalence of LAMA and LABA drugs once daily in terms of FEV1 [38, 41-43].

Does the addition of an ICS to a bronchodilator further reduce exacerbations?

Pooled data from two trials of the once-daily ICS fluticasone furoate added to the once-daily LABA vilanterol suggest that the answer to this question is "yes". Combination ICS/LABA treatment reduced exacerbations by approximately $20 \%$ and was most evident when the $100 / 25-\mu \mathrm{g}$ dose of this combination was used [44]. The decreased exacerbation rate was seen even when the inhaled steroid did not improve FEV1, suggesting that the corticosteroid effect may be mediated by mechanisms independent of lung function change. Adding budesonide/formoterol twice daily to tiotropium decreased morning symptoms and exacerbations over the 3 months of the CLIMB trial [45] but more studies examining the benefits of ICS in addition to dual bronchodilator treatment are needed. The recently reported Withdrawal of Inhaled Steroids during Optimized Bronchodilator Management (WISDOM) study demonstrated that ICS can be safely withdrawn if dual bronchodilators are provided, which may provide further insights into how many people need this form of anti-inflammatory therapy [46]. 
Can systemic anti-inflammatory agents, such as phosphodiesterase-4 inhibitors, reduce exacerbations?

Our answer from the data available in 2007 was "no" [15] but this has now changed since a more specific "at risk" group of COPD patients with phenotypically severe disease, a history of chronic bronchitis and exacerbations has been studied [47]. This, again, highlights an evolution in better matching treatment to patient phenotype. The only licensed drug in this class, roflumilast, reduced the number of corticosteroid-treated exacerbations by $\sim 17 \%$, and improved lung function and exacerbation rate, irrespective of the use of long-acting inhaled bronchodilators [48]. Pooled data analysis from the original studies showed that roflumilast was of particular benefit to people with more frequent exacerbations at baseline and, in general, roflumilast treatment shifted patients from a frequent to an infrequent exacerbation phenotype [48]. However, it remains unclear whether roflumilast treatment will reduce exacerbations in patients receiving ICS/LABA or triple-therapy treatment, a point which should be resolved when the results of the REACT study are reported [49].

\section{Do long-term antibiotics reduce exacerbation rates?}

Three trials have addressed this question, with fairly consistently positive results. SeEmungal et al. [50] studied 109 patients receiving twice-daily erythromycin or placebo and found fewer exacerbations in patients treated with antibiotics. This was confirmed in the larger, 1-year, US National Heart, Lung, and Blood Institute-funded study by AlBerT et al. [51] where a 27\% reduction in exacerbations was reported. In a further study, intermittent treatment with antibiotics failed to improve the pre-specified primary end-point of clinical response on day 30, defined as a cure or improvement in symptoms, but did decrease the exacerbation rate [52]. Despite these encouraging results, there remain significant concerns about the unrestricted prescription of antibiotic prophylaxis. To date, studies have only lasted 1 year and there have been concerns about the cardiovascular safety of using azithromycin in acute infections [53]. However, a greater worry is the risk of generating wide-spread antibiotic resistance, something which has already been seen with intermittent macrolide prescription, in an era of a dwindling antibiotic development pipeline $[51,54]$. Further studies to define which patients are most likely to benefit (in order to try to restrict antibiotic use to these individuals [55]), and which antibiotic has the best risk/benefit ratio in terms of safety and antibiotic resistance induction are urgently needed.

\section{Unexpected benefits from RCTs}

Classically, RCTs are designed to answer a single important question well. However, important observations have been made from the secondary analysis of RCT data and these have influenced how we manage COPD. Although UPLIFT was primarily a study that hoped to modify the rate of decline of lung function with bronchodilators [18], it also undertook careful follow-up of all participants on an intention-to-treat basis. As a result, it gave a clear signal about the potential benefits of bronchodilator therapy on mortality, which was significantly lower at the end of the randomised treatment period [56]. TORCH, which was designed to determine whether anti-inflammatory therapy could modify mortality [17], coincidentally provided data on lung function decline and is likely to be the last placebo-controlled analysis of treatment on lung function decline in severe disease [57]. This pre-planned analysis of the TORCH data showed that all active treatments decreased the rate of decline in FEV1 to $~ 70 \%$ of that seen in placebo-treated subjects, with little difference between each of the active therapies. How much of this benefit is due to the selective loss of the sicker placebo patients from follow-up is unclear. TORCH, however, provides the best evidence to date for the effect of drug treatment on disease progression. Interestingly, when the UPLIFT analysis was restricted to patients without background medication, tiotropium also reduced the rate of decline in FEV1 [58]. Like bronchodilator responsiveness [26], the rate of decline in FEV1 varies depending on the baseline lung function, being most rapid in those who have less severe FEV1 impairment [57]. This idea is supported by a recent post hoc review of the original Lung Health Study data, where those with the mildest disease and airflow obstruction showed the most rapid loss of lung function [59]. These observations will inevitably alter the thresholds for entry into future COPD trials.

Both TORCH and UPLIFT identified treatment effects in patients with spirometrically less severe COPD, with benefits in terms of exacerbation numbers and lung function decline [17, 18]. Similarly, each study identified a marked seasonal difference of the risk of exacerbations, at least in temperate climates, a finding supported by further analysis of the POET-COPD trial data [60]. These data have implications for both healthcare planning and clinical trial design.

Finally, UPLIFT confirmed that differential dropout of patients randomised to placebo still occurs even when corticosteroid withdrawal was not undertaken [18], making loss of patients in a randomised study an important surrogate marker for perceived treatment benefit. Analysis of the TORCH dataset to determine selective patient loss showed those exacerbating more than twice or whose SGRQ score deteriorates by $>6$ units over time are the most likely to withdraw [61, 62]. 
Other large studies have generated interesting secondary analyses. The POET-COPD trial investigators identified a specific genetic difference in patients who were more likely to benefit from being given a LAMA than a LABA treatment [63]. The utility of this in routine practice, when personalised medicine is in vogue, remains unclear.

\section{Drug safety}

As well as establishing efficacy, large RCTs provide a robust database to search for adverse events, both suspected and unanticipated. Particular attention was paid during the TORCH study to the risk of osteoporosis and cataracts in patients receiving ICS [17]. Detailed follow-up of bone mineral density and eye examinations suggested that there was no increased risk of these $[17,64]$ although the high background rate of bone and eye disease, as common comorbidities in COPD may obscure such signals. TORCH identified an increased risk of pneumonia in patients randomised to ICS [65], which was confirmed by the INSPIRE data [66]. These events occurred in older patients with more severe COPD, but baseline demographics did not predict individuals at particular risk of developing pneumonia when being given ICS. Review of the diary card data from the INSPIRE study suggests that the excess of pneumonic events with ICS treatment was due to a failure to improve after reported or unreported COPD exacerbation [66]. Prospective radiological data were not collected in these earlier studies but were included as part of the fluticasone furoate programme and confirmed that this ICS was also associated with radiologically confirmed pneumonia [44]. Whether the same holds true of budesonide- rather than fluticasone-related compounds is less clear. Data from a pooled analysis of 1-year budesonide studies in COPD showed no increase in the risk of pneumonia [67], a finding supported by a subsequent database study [68]. Recent data on fluticasone furoate-vilanterol suggest that some individuals are more likely to develop pneumonia [69]. Those with a low body mass index and prior pneumonia history with lower lung function levels (FEV1 $<40 \%$ predicted) had an odds ratio of pneumonia events 15 times that of milder-stage, better-nourished patients. Closer scrutiny of these data also highlights a very low rate of pneumococcal vaccination of $20 \%$ or less in study participants. Collectively, these data may be unexpectedly useful in day-to-day management of such patients but, as yet, do not reliably identify those at particular risk of pneumonia with ICS therapy. Hopefully, they will prompt clinicians to discuss vaccination with their patients.

There are still concerns about the cardiovascular safety of bronchodilator treatment. The TORCH data were reassuring, finding no increased risk of death in LABA-treated patients at risk of cardiovascular disease and a lower overall cardiovascular mortality in those treated with ICS [70]. Concerns about the potential risks of inhaled antimuscarinic drugs were raised at the time of the publication of UPLIFT, although this large database and analysis of other pooled tiotropium data subsequently reassured regulators that there was no increased hazard [18, 56, 71]. Although a meta-analysis of the Respimat Soft Mist inhaler (Boehringer Ingleheim, Ingelheim, Germany) suggested that there was an increased risk of dying compared with placebo [72], this was refuted in a very large direct comparison of tiotropium via the HandiHaler (Boehringer Ingelheim) with Respimat in two doses, which formed the basis of the TIOSPIR trial [19]. Again, these data were reassuring, with the highest dose of tiotropium delivered by soft mist having the lowest mortality in the study.

Other drugs used in COPD have pharmacologically predictable side-effects such as roflumilast with headaches, diarrhoea and nausea, which led to a significant number of patient withdrawals at the early stages of treatment $[47,73]$.

\section{Observational studies}

Not all questions can be answered by RCTs and sometimes new knowledge is needed to stimulate treatment innovation. The last 5 years have seen increased enthusiasm for observational studies, where generally large cohorts of patients are followed (opportunistically) in healthcare databases or more robustly in smaller but more rigorously defined studies with assessment of a variety of physiological, radiological and biochemical outcomes. The best known, ECLIPSE [74] and COPDGene [75], have prospectively recruited large numbers of patients ( 2100 and $>10000$, respectively). A range of new genes has been identified [76] but the main clinical gains have come from a better understanding of the clinical phenotypes and predictors of disease progression [77], which have been recently reviewed [78, 79].

ECLIPSE showed that not all patients had progressive lung function decline over the 3 years of follow-up, with only $38 \%$ of individuals losing $40 \mathrm{~mL}$ of FEV1 per year [80]. This change related to the number of exacerbations the patient experienced, initial bronchodilator responsiveness and the serum club cell secretory protein (CC-16). The presence of exacerbations also identified a more rapid loss of lung tissue on serial computed tomography (CT), in the first study to describe lung tissue loss of this nature in unselected COPD patients [81]. 
These observational studies identified a specific "frequent exacerbator" phenotype, a finding that has impacted upon the design of many subsequent studies and also on treatment guidance [71, 82]. The ECLIPSE data suggested that this phenotype was relatively stable and could be identified from the prior exacerbation history and the presence of gastro-oesophageal reflux. The importance of exacerbation history was confirmed in the COPDGene data [83], which also identified the importance of subclinical pulmonary vascular disease where individuals with a pulmonary artery to aorta ratio $>1$ on CT scanning were more likely to experience an exacerbation [84].

The BODE (body mass index, airflow obstruction, dyspnoea and exercise capacity) index is a good predictor of mortality in COPD [85], which might be augmented by additional biomarker data. This hypothesis was tested by measuring multiple inflammatory biomarkers, with mildly positive results [86]. However, most of the predictive value lay with the clinical variables. The mortality data were also used to define the minimum important distance from the 6-min walking distance, which was $30 \mathrm{~m}$ [87], a finding similar to that from studies using other ways of deriving this number [88].

Many observational studies have tried to identify specific inflammatory subtypes of COPD patients, and some data suggest that inflammatory biomarkers are associated with exacerbations and can predict outcomes $[89,90]$. This appears to hold true in populations, but at an individual level, the results are rather disappointing, reflecting the poor reproducibility of most biomarkers [91]. This has led to the concept that groups of inflammatory markers might indicate a persistently inflamed state, although the individual abnormalities might vary from time to time [91]. Selecting people in this way did seem to identify those with a higher exacerbation rate in the ECLIPSE study [91] but operationalising this sort of observation remains both difficult and debatable.

There is much less disagreement about the heterogeneous nature of COPD [92-94] or its association with other significant pathologies, especially cardiovascular, metabolic, psychological and bone-related problems $[95,96]$. The observational cohorts have impacted COPD guidance and have also provided data to determine whether the new proposed Global Initiative for Chronic Obstructive Lung Disease (GOLD) classification [97] is clinically useful. This has been discussed in detail by the authors and it is clear that there are some limitations to the newly proposed system $[98,99]$. Although patients in GOLD group B are considered to be symptomatic but at low risk of events, their mortality is very similar to the less symptomatic but exacerbation-prone group C patients [100]. Understanding the relative occurrence of such groups is going to be important and is clearly influenced by whether patients are studied in the community setting or in a hospital clinic. Further analysis of large cohort studies should clarify this issue.

The observational studies discussed so far were specifically assembled to answer questions about the natural history of COPD and its genetic predictors. However, there are clear advantages in terms of expense and representativeness in creating cohorts "in silico" from data already available in administrative databases. These real-world studies have great potential for generalisability, but despite considerable effort by their authors to match comparable groups, they are still prone to a number of potential biases. Nonetheless, they generate important hypotheses and sometimes provide the only regulatory-approved and acceptable evidence of the hazards of drug treatment. Sometimes, these reports agree well with data from more specifically generated RCTs, as is the case for the increased risk of pneumonia with ICS [67, 101, 102]. The outcomes of ICS-treated patients admitted with pneumonia are no worse than those not receiving this therapy. These studies also offer the real-world potential to compare different therapies which might not be conducted in RCTs [68]. Such comparative studies can have value, although this may be limited to propensity or case matching for known or available data.

Databases can identify areas of additional uncertainty. Although the large TIOSPIR RCT excluded an increased mortality in patients taking tiotropium by soft-mist formulation [19], there might be a risk in individuals with impaired renal function, as suggested by the results of a Dutch study [103].

\section{What clinical trials do we need in the future?}

Despite the progress reported here, many questions remain unanswered. We need more data about the natural history of "early" COPD, when the degree of spirometric impairment is mild. The systematic characterisation of airway inflammation and structural lung changes remains to be performed, nor is it clear whether anti-inflammatory treatment accelerates or permits the resolution of airway inflammation after smoking cessation. This is amenable to study and is a priority if we are to intervene before major structural damage occurs. Similarly, COPD in nonsmokers especially in developing countries needs to be better characterised, as recent reports suggest it follows a different clinical course [104].

We need clarity about how to use the plethora of new inhaled drugs in COPD. Specifically, we need one or more adequately powered trials testing whether two long-acting inhaled bronchodilators are better than either alone, especially the LAMA component. The SPARK data suggest that this may be true [40] but are 
not conclusive. Similarly, the selection of patients responsive to and at risk of side-effects from ICS must be addressed. Preliminary data suggest that the response to acute exacerbations differs depending on baseline eosinophil count [105] but prospectively collected data defining the sensitivity and specificity of eosinophil-guided treatment are needed. More trials to establish whether therapy can be reduced once patients are clinically stable, similar to the WISDOM study [46], would also inform future management. Additional data to define the place of phosphodiesterase- 4 inhibition in severe COPD, and the best way to introduce this therapy without producing side-effects, would be welcome, as would studies that target long-term antibiotic prophylaxis to patients at high risk of exacerbation. If this were coupled with better data about the risks of antimicrobial resistance, then a true risk/benefit analysis of this potentially important therapy would be possible. Several other possible options are listed in table 2.

\section{TABLE 2 Future studies awaited or needed}

Expected reporting

\section{RCTs}

Large-scale RCT of theophylline added to ICS therapy

Large-scale RCT of roflumilast in those already on ICS/LABA

Large-scale cardiovascular safety of emerging ICS/LABA, LAMA and triple therapies in COPD patients with elevated cardiovascular risk

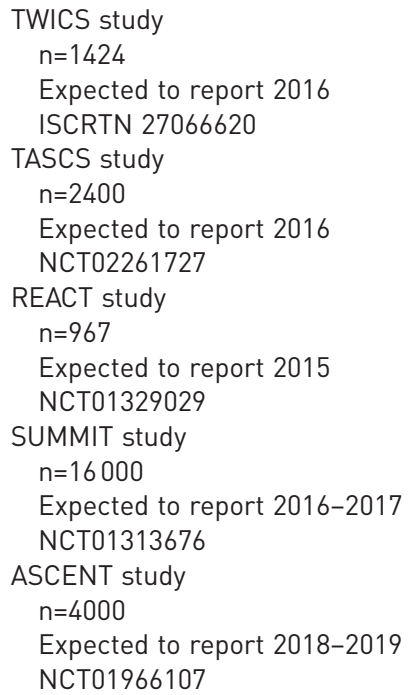

Further studies of triple therapy versus LABA/LAMA in GOLD groups $\mathrm{B}$ and $\mathrm{C}$

Large-scale studies of MABA versus ICS/LABA/LAMA versus LABA/LAMA

Large-scale studies of biological therapies targeting ICS/LABA triple therapy-treated patients who still exacerbate

Large-scale studies of novel anti-inflammatory agents (CXCR2 inhibitors, p38 MAPK inhibitors and PI3K inhibitors)

\section{Pragmatic RCTs}

Comparative study of new ICS/LABA to current standard therapy

\author{
Benralizumab (GALATHEA study) \\ $\mathrm{n}=1743$ \\ Expected to report 2017-2018 \\ NCT02138916
}

\author{
Salford Lung Study \\ $n=7000$ \\ Expected to report 2016-2017 \\ NCT01551758
}

\footnotetext{
Observational studies

Mortality and long-term safety studies of new therapies in patients with COPD and multiple comorbidities

Long-term safety and emergence of resistant pathogens with chronic macrolide use

Pneumonia risks in ICS-treated COPD patients already treated with pneumococcal vaccination
}

RCT: randomised controlled trial; ICS: inhaled corticosteroids; TWICS: Theophylline with Inhaled Corticosteroid; ISRCTN: international standard randomised controlled trial number; TASCS: Theophylline and Steroids in Chronic Obstructive Pulmonary Disease Study; NCT: www. clinicaltrials.gov identifier number; LABA: long-acting $\beta$-agonist; LAMA: long-acting muscarinic antagonist; COPD: chronic obstructive pulmonary disease; SUMMIT: Study to Understand Mortality and Morbidity in COPD; GOLD: Global Initiative for Chronic Obstructive Lung Disease; MABA: muscarinic antagonist- $\beta$-agonist; MAP: mitogen-activated protein kinase; PI3K: phosphatidyl inositol 3-kinase. 
As noted previously, RCTs do not necessarily tell us how effectively a treatment will be used in the real world of clinical practice and observations based on review of administrative databases are always at risk of being biased by the differences that led a physician to prescribe one treatment over another.

One exciting possibility is of using computerised systems of care to randomly assign a treatment and follow patient progress in their electronic medical records. This form of pragmatic RCT applied in routine practice is only possible when there is true equipoise between treatment options, a condition that occurs rather more often than many clinicians and pharmaceutical companies would allow. Obtaining data in this way may provide our best chance of fully understanding how effective our treatments are and what the real value to improving patient care might be. Such trials would not replace the need to have appropriately conducted RCTs but rather would complement such trials and, hopefully, allow us to develop a more responsive way of understanding how treatment can affect patients with a chronic disease such as COPD.

\section{Acknowledgements}

Both authors acknowledge the support and advice from members of the UK National Institute for Health Research National Respiratory Disorders trial group, who have conducted many of the aforementioned studies.

\section{References}

1 Mathers CD, Loncar D. Projections of global mortality and burden of disease from 2002 to 2030. PLoS Med 2006; 3: e442.

2 Murray CJ, Vos T, Lozano R, et al. Disability-adjusted life years (DALYs) for 291 diseases and injuries in 21 regions, 1990-2010: a systematic analysis for the Global Burden of Disease Study 2010. Lancet 2012; 380: 2197-2223.

3 Vos T, Flaxman AD, Naghavi M, et al. Years lived with disability (YLDs) for 1160 sequelae of 289 diseases and injuries 1990-2010: a systematic analysis for the Global Burden of Disease Study 2010. Lancet 2012; 380: 2163-2196.

4 Salvi SS, Barnes PJ. Chronic obstructive pulmonary disease in non-smokers. Lancet 2009; 374: 733-743.

5 Lokke A, Lange P, Scharling H, et al. Developing COPD: a 25 year follow up study of the general population. Thorax 2006; 61: 935-939.

6 Wu J, Sin DD. Improved patient outcome with smoking cessation: when is it too late? Int J Chron Obstruct Pulmon Dis 2011; 6: 259-267.

7 Godtfredsen NS, Lam TH, Hansel TT, et al. COPD-related morbidity and mortality after smoking cessation: status of the evidence. Eur Respir J 2008; 32: 844-853.

8 Dickens JA, Miller BE, Edwards LD, et al. COPD association and repeatability of blood biomarkers in the ECLIPSE cohort. Respir Res 2011; 12: 146.

9 Vestbo J, Anderson W, Coxson HO, et al. Evaluation of COPD Longitudinally to Identify Predictive Surrogate End-points (ECLIPSE). Eur Respir J 2008; 31: 869-873.

10 Keene ON, Vestbo J, Anderson JA, et al. Methods for therapeutic trials in COPD: lessons from the TORCH trial. Eur Respir J 2009; 34: 1018-1023.

11 Hannan EL. Randomized clinical trials and observational studies: guidelines for assessing respective strengths and limitations. JACC Cardiovasc Interv 2008; 1: 211-217.

12 Kesten S, Plautz M, Piquette CA, et al. Premature discontinuation of patients: a potential bias in COPD clinical trials. Eur Respir J 2007; 30: 898-906.

13 Rawlins M. De testimonio: on the evidence for decisions about the use of therapeutic interventions. Clin Med 2008; 8: 579-588.

14 Saturni S, Bellini F, Braido F, et al. Randomized controlled trials and real life studies. Approaches and methodologies: a clinical point of view. Pulm Pharmacol Ther 2014; 27: 129-138.

15 Calverley PM, Rennard SI. What have we learned from large drug treatment trials in COPD? Lancet 2007; 370: 774-785.

16 O'Reilly J, Jones MM, Parnham J, et al. Management of stable chronic obstructive pulmonary disease in primary and secondary care: summary of updated NICE guidance. BMJ 2010; 340: c3134.

17 Calverley PM, Anderson JA, Celli B, et al. Salmeterol and fluticasone propionate and survival in chronic obstructive pulmonary disease. N Engl J Med 2007; 356: 775-789.

18 Tashkin DP, Celli B, Senn S, et al. A 4-year trial of tiotropium in chronic obstructive pulmonary disease. $N$ Engl J Med 2008; 359: 1543-1554.

19 Wise RA, Anzueto A, Cotton D, et al. Tiotropium Respimat inhaler and the risk of death in COPD. $N$ Engl J Med 2013; 369: 1491-1501.

20 Hurst JR, Donaldson GC, Quint JK, et al. Temporal clustering of exacerbations in chronic obstructive pulmonary disease. Am J Respir Crit Care Med 2009; 179: 369-374.

21 Keene ON, Calverley PM, Jones PW, et al. Statistical analysis of exacerbation rates in COPD: TRISTAN and ISOLDE revisited. Eur Respir J 2008; 32: 17-24.

22 Vogelmeier C, Hederer B, Glaab T, et al. Tiotropium versus salmeterol for the prevention of exacerbations of COPD. N Engl J Med 2011; 364: 1093-1103.

23 Leidy NK, Wilcox TK, Jones PW, et al. Development of the EXAcerbations of Chronic Obstructive Pulmonary Disease Tool (EXACT): a patient-reported outcome (PRO) measure. Value Health 2010; 13: 965-975.

24 Calverley PM, Burge PS, Spencer S, et al. Bronchodilator reversibility testing in chronic obstructive pulmonary disease. Thorax 2003; 58: 659-664.

25 Tashkin DP, Li N, Halpin D, et al. Annual rates of change in pre- vs. post-bronchodilator FEV1 and FVC over 4 years in moderate to very severe COPD. Respir Med 2013; 107: 1904-1911.

26 Albert P, Agusti A, Edwards L, et al. Bronchodilator responsiveness as a phenotypic characteristic of established chronic obstructive pulmonary disease. Thorax 2012; 67: 701-708. 
Calverley PM, Albert P, Walker PP. Bronchodilator reversibility in chronic obstructive pulmonary disease: use and limitations. Lancet Respir Med 2013; 1: 564-573.

Fishman A, Martinez F, Naunheim K, et al. A randomized trial comparing lung-volume-reduction surgery with medical therapy for severe emphysema. N Engl J Med 2003; 348: 2059-2073.

Criner GJ. Alternatives to lung transplantation: lung volume reduction for COPD. Clin Chest Med 2011; 32: 379-397.

Herth FJ, Noppen M, Valipour A, et al. Efficacy predictors of lung volume reduction with Zephyr valves in a European cohort. Eur Respir J 2012; 39: 1334-1342.

Deslee G, Klooster K, Hetzel M, et al. Lung volume reduction coil treatment for patients with severe emphysema: a European multicentre trial. Thorax 2014; 69: 980-986.

Gompelmann D, Eberhardt R, Slebos DJ, et al. Diagnostic performance comparison of the Chartis System and high-resolution computerized tomography fissure analysis for planning endoscopic lung volume reduction. Respirology 2014; 19: 524-530.

Sciurba FC, Ernst A, Herth FJ, et al. A randomized study of endobronchial valves for advanced emphysema. N Engl J Med 2010; 363: 1233-1244.

Jones PW, Harding G, Berry P, et al. Development and first validation of the COPD Assessment Test. Eur Respir J 2009; 34: 648-654.

Wedzicha JA, Calverley PM, Seemungal TA, et al. The prevention of chronic obstructive pulmonary disease exacerbations by salmeterol/fluticasone propionate or tiotropium bromide. Am J Respir Crit Care Med 2008; 177: $19-26$.

Mahler DA, D'Urzo A, Bateman ED, et al. Concurrent use of indacaterol plus tiotropium in patients with COPD provides superior bronchodilation compared with tiotropium alone: a randomised, double-blind comparison. Thorax 2012; 67: 781-788.

Vogelmeier C, Ramos-Barbon D, Jack D, et al. Indacaterol provides 24-hour bronchodilation in COPD: a placebo-controlled blinded comparison with tiotropium. Respir Res 2010; 11: 135.

Buhl R, Dunn LJ, Disdier C, et al. Blinded 12-week comparison of once-daily indacaterol and tiotropium in COPD. Eur Respir J 2011; 38: 797-803.

Donohue JF, Fogarty C, Lotvall J, et al. Once-daily bronchodilators for chronic obstructive pulmonary disease: indacaterol versus tiotropium. Am J Respir Crit Care Med 2010; 182: 155-162.

Wedzicha JA, Decramer M, Ficker JH, et al. Analysis of chronic obstructive pulmonary disease exacerbations with the dual bronchodilator QVA149 compared with glycopyrronium and tiotropium (SPARK): a randomised, double-blind, parallel-group study. Lancet Respir Med 2013; 1: 199-209.

Rossi A, Centanni S, Cerveri I, et al. Acute effects of indacaterol on lung hyperinflation in moderate COPD: a comparison with tiotropium. Respir Med 2012; 106: 84-90.

Kew KM, Dias S, Cates CJ. Long-acting inhaled therapy (beta-agonists, anticholinergics and steroids) for COPD: a network meta-analysis. Cochrane Database Syst Rev 2014; 3: CD010844.

Decramer M, Anzueto A, Kerwin E, et al. Efficacy and safety of umeclidinium plus vilanterol versus tiotropium, vilanterol, or umeclidinium monotherapies over 24 weeks in patients with chronic obstructive pulmonary disease: results from two multicentre, blinded, randomised controlled trials. Lancet Respir Med 2014; 2: 472-486.

Dransfield MT, Bourbeau J, Jones PW, et al. Once-daily inhaled fluticasone furoate and vilanterol versu vilanterol only for prevention of exacerbations of COPD: two replicate double-blind, parallel-group, randomised controlled trials. Lancet Respir Med 2013; 1: 210-223.

Welte T, Miravitlles M, Hernandez P, et al. Efficacy and tolerability of budesonide/formoterol added to tiotropium in patients with chronic obstructive pulmonary disease. Am J Respir Crit Care Med 2009; 180: 741-750.

Magnussen H, Disse B, Rodriguez-Roisin R, et al. Withdrawal of inhaled glucocorticoids and exacerbations of COPD. N Engl J Med 2014; 371: 1285-1294.

Calverley PM, Rabe KF, Goehring UM, et al. Roflumilast in symptomatic chronic obstructive pulmonary disease: two randomised clinical trials. Lancet 2009; 374: 685-694.

Wedzicha JA, Rabe KF, Martinez FJ, et al. Efficacy of roflumilast in the COPD frequent exacerbator phenotype. Chest 2013; 143: 1302-1311.

Calverley PM, Martinez FJ, Fabbri LM, et al. Does roflumilast decrease exacerbations in severe COPD patients not controlled by inhaled combination therapy? The REACT study protocol. Int J Chron Obstruct Pulmon Dis 2012; 7: 375-382.

Seemungal TA, Wilkinson TM, Hurst JR, et al. Long-term erythromycin therapy is associated with decreased chronic obstructive pulmonary disease exacerbations. Am J Respir Crit Care Med 2008; 178: 1139-1147.

Albert RK, Connett J, Bailey WC, et al. Azithromycin for prevention of exacerbations of COPD. N Engl J Med 2011; 365: 689-698. obstructive pulmonary disease: a randomized controlled trial. Respir Res 2010; 11: 10.

Ray WA, Murray KT, Hall K, et al. Azithromycin and the risk of cardiovascular death. N Engl J Med 2012; 366: 1881-1890.

Serisier DJ. Risks of population antimicrobial resistance associated with chronic macrolide use for inflammatory airway diseases. Lancet Respir Med 2013; 1: 262-274.

Han MK, Tayob N, Murray S, et al. Predictors of chronic obstructive pulmonary disease exacerbation reduction in response to daily azithromycin therapy. Am J Respir Crit Care Med 2014; 189: 1503-1508.

Celli B, Decramer M, Kesten S, et al. Mortality in the 4-year trial of tiotropium (UPLIFT) in patients with chronic obstructive pulmonary disease. Am J Respir Crit Care Med 2009; 180: 948-955.

Celli BR, Thomas NE, Anderson JA, et al. Effect of pharmacotherapy on rate of decline of lung function in chronic obstructive pulmonary disease: results from the TORCH study. Am J Respir Crit Care Med 2008; 178: 332-338.

Troosters T, Celli B, Lystig T, et al. Tiotropium as a first maintenance drug in COPD: secondary analysis of the UPLIFT trial. Eur Respir J 2010; 36: 65-73.

Drummond MB, Hansel NN, Connett JE, et al. Spirometric predictors of lung function decline and mortality in early chronic obstructive pulmonary disease. Am J Respir Crit Care Med 2012; 185: 1301-1306. 
Rabe KF, Fabbri LM, Vogelmeier C, et al. Seasonal distribution of COPD exacerbations in the Prevention of Exacerbations with Tiotropium in COPD trial. Chest 2013; 143: 711-719.

Vestbo J, Anderson JA, Calverley PM, et al. Bias due to withdrawal in long-term randomised trials in COPD: evidence from the TORCH study. Clin Respir J 2011; 5: 44-49.

Jones PW, Anderson JA, Calverley PMA, et al. Health status in the TORCH study of COPD: treatment efficacy and other determinants of change. Respir Res 2011; 12: 71.

Rabe KF, Fabbri LM, Israel E, et al. Effect of ADRB2 polymorphisms on the efficacy of salmeterol and tiotropium in preventing COPD exacerbations: a prespecified substudy of the POET-COPD trial. Lancet Respir Med 2014; 2: 44-53.

Ferguson GT, Calverley PM, Anderson JA, et al. Prevalence and progression of osteoporosis in patients with COPD: results from the TOwards a Revolution in COPD Health study. Chest 2009; 136: 1456-1465.

Crim C, Calverley PM, Anderson JA, et al. Pneumonia risk in COPD patients receiving inhaled corticosteroids alone or in combination: TORCH study results. Eur Respir J 2009; 34: 641-647.

Calverley PM, Stockley RA, Seemungal TA, et al. Reported pneumonia in patients with COPD: findings from the INSPIRE study. Chest 2011; 139: 505-512.

Sin DD, Tashkin D, Zhang X, et al. Budesonide and the risk of pneumonia: a meta-analysis of individual patient data. Lancet 2009; 374: 712-719.

Janson C, Larsson K, Lisspers $\mathrm{KH}$, et al. Pneumonia and pneumonia related mortality in patients with COPD treated with fixed combinations of inhaled corticosteroid and long acting $\beta_{2}$ agonist: observational matched cohort study (PATHOS). BMJ 2013; 346: f3306.

DiSantostefano RL, Li H, Hinds D, et al. Risk of pneumonia with inhaled corticosteroid/long-acting $\beta 2$ agonist therapy in chronic obstructive pulmonary disease: a cluster analysis. Int J Chron Obstruct Pulmon Dis 2014; 9: 457-468.

Calverley PM, Anderson JA, Celli B, et al. Cardiovascular events in patients with COPD: TORCH study results. Thorax 2010; 65: 719-725.

Rodrigo GJ, Castro-Rodriguez JA, Nannini LJ, et al. Tiotropium and risk for fatal and nonfatal cardiovascular events in patients with chronic obstructive pulmonary disease: systematic review with meta-analysis. Respir Med 2009; 103: 1421-1429.

Singh S, Loke YK, Enright PL, et al. Mortality associated with tiotropium mist inhaler in patients with chronic obstructive pulmonary disease: systematic review and meta-analysis of randomised controlled trials. BMJ 2011; 342: d3215.

Fabbri LM, Calverley PM, Izquierdo-Alonso JL, et al. Roflumilast in moderate-to-severe chronic obstructive pulmonary disease treated with longacting bronchodilators: two randomised clinical trials. Lancet 2009; 374: 695-703.

Agusti A, Calverley PM, Celli B, et al. Characterisation of COPD heterogeneity in the ECLIPSE cohort. Respir Res 2010; 11: 122 .

Regan EA, Hokanson JE, Murphy JR, et al. Genetic epidemiology of COPD (COPDGene) study design. COPD 2010; 7: 32-43.

Pillai SG, Kong X, Edwards LD, et al. Loci identified by genome-wide association studies influence different disease-related phenotypes in chronic obstructive pulmonary disease. Am J Respir Crit Care Med 2010; 182: $1498-1505$.

Hurst JR, Vestbo J, Anzueto A, et al. Susceptibility to exacerbation in chronic obstructive pulmonary disease. $N$ Engl J Med 2010; 363: 1128-1138.

Vestbo J, Agusti A, Wouters EF, et al. Should we view chronic obstructive pulmonary disease differently after ECLIPSE? A clinical perspective from the study team. Am J Respir Crit Care Med 2014; 189: 1022-1030.

Faner R, Tal-Singer R, Riley JH, et al. Lessons from ECLIPSE: a review of COPD biomarkers. Thorax 2014; 69: 666-672.

Vestbo J, Edwards LD, Scanlon PD, et al. Changes in forced expiratory volume in 1 second over time in COPD. N Engl J Med 2011; 365: 1184-1192.

Coxson HO, Dirksen A, Edwards LD, et al. The presence and progression of emphysema in COPD as determined by CT scanning and biomarker expression: a prospective analysis from the ECLIPSE study. Lancet Respir Med 2013; 1: 129-136.

Vestbo J, Hurd SS, Agusti AG, et al. Global strategy for the diagnosis, management, and prevention of chronic obstructive pulmonary disease: GOLD executive summary. Am J Respir Crit Care Med 2013; 187: 347-365.

Han MK, Kazerooni EA, Lynch DA, et al. Chronic obstructive pulmonary disease exacerbations in the COPDGene study: associated radiologic phenotypes. Radiology 2011; 261: 274-282.

Wells JM, Washko GR, Han MK, et al. Pulmonary arterial enlargement and acute exacerbations of COPD. N Engl J Med 2012; 367: 913-921.

Cote CG, Pinto-Plata VM, Marin JM, et al. The modified BODE index: validation with mortality in COPD. Eur Respir J 2008; 32: 1269-1274.

Celli BR, Locantore N, Yates J, et al. Inflammatory biomarkers improve clinical prediction of mortality in chronic obstructive pulmonary disease. Am J Respir Crit Care Med 2012; 185: 1065-1072.

Polkey MI, Spruit MA, Edwards LD, et al. Six-minute-walk test in chronic obstructive pulmonary disease: minimal clinically important difference for death or hospitalization. Am J Respir Crit Care Med 2013; 187: 382-386.

Puhan MA, Mador MJ, Held U, et al. Interpretation of treatment changes in 6-minute walk distance in patients with COPD. Eur Respir J 2008; 32: 637-643.

Thomsen M, Ingebrigtsen TS, Marott JL, et al. Inflammatory biomarkers and exacerbations in chronic obstructive pulmonary disease. JAMA 2013; 309: 2353-2361.

0 Kersul AL, Iglesias A, Rios A, et al. Molecular mechanisms of inflammation during exacerbations of chronic obstructive pulmonary disease. Arch Bronconeumol 2011; 47: 176-183.

Agusti A, Edwards LD, Rennard SI, et al. Persistent systemic inflammation is associated with poor clinical outcomes in COPD: a novel phenotype. PLoS One 2012; 7: e37483.

Wedzicha JA. The heterogeneity of chronic obstructive pulmonary disease. Thorax 2000; 55: 631-632. 
Reilly JJ. COPD and declining FEV1 - time to divide and conquer? N Engl J Med 2008; 359: 1616-1618.

Beasley R, Weatherall M, Travers J, et al. Time to define the disorders of the syndrome of COPD. Lancet 2009; 374: $670-672$

Mannino DM, Thorn D, Swensen A, et al. Prevalence and outcomes of diabetes, hypertension and cardiovascular disease in COPD. Eur Respir J 2008; 32: 962-969. matter? Eur Respir Rev 2014; 23: 131-141.

Global Initiative for Chronic Obstructive Lung Disease. Global Strategy for the Diagnosis, Management, and Prevention of Chronic Obstructive Pulmonary Disease. www.goldcopd.org/uploads/users/files/GOLD_Report_ 2015.pdf Date last updated: 2015.

Agusti A, Edwards LD, Celli B, et al. Characteristics, stability and outcomes of the 2011 GOLD COPD groups in the ECLIPSE cohort. Eur Respir J 2013; 42: 636-646.

Calverley PM. The ABCD of GOLD made clear. Eur Respir J 2013; 42: 1163-1165.

Agusti A, Hurd S, Jones P, et al. FAQs about the GOLD 2011 assessment proposal of COPD: a comparative analysis of four different cohorts. Eur Respir J 2013; 42: 1391-1401.

Suissa S, Patenaude V, Lapi F, et al. Inhaled corticosteroids in COPD and the risk of serious pneumonia. Thorax 2013; 68: 1029-1036.

Singanayagam A, Chalmers JD, Akram AR, et al. Impact of inhaled corticosteroid use on outcome in COPD patients admitted with pneumonia. Eur Respir J 2011; 38: 36-41.

Verhamme KM, Afonso A, Romio S, et al. Use of tiotropium Respimat Soft Mist Inhaler versus HandiHaler and mortality in patients with COPD. Eur Respir J 2013; 42: 606-615.

Ramirez-Venegas A, Sansores RH, Quintana-Carrillo RH, et al. FEV1 decline in patients with chronic obstructive pulmonary disease associated with biomass exposure. Am J Respir Crit Care Med 2014; 190: 996-1002.

Bafadhel M, Davies L, Calverley PM, et al. Blood eosinophil guided prednisolone therapy for exacerbations of COPD: a further analysis. Eur Respir J 2014; 44: 789-791. 